Jurnal Sulolipu : Media Komunikasi Sivitas Akademika dan Masyarakat

Vol. 21 No.12021

e-issn: 2622-6960, p-issn : 0854-624X

\title{
KEMAMPUAN TRAY AERATOR FILTER ZEOLIT DALAM MENURUNKAN KADAR BESI (Fe) DAN MANGAN (Mn) PADA AIR BERSIH
}

Ability Of Tray Aerator And Zeolite Filter In Reducing Iron (Fe) And Manganese (Mn)

In Clean Water

(Study of literature)

Ronny ${ }^{1}$, Muh. Inggar Mahawira ${ }^{2}$

1,2Dosen Poltekkes Kemenkes Makassar

ronnymuntu@gmail.com,/,085255666746

\begin{abstract}
Water is a need that cannot be postponed. The main problems faced by water resources include the quantity of water that is no longer able to meet the increasing demand and the decreasing quality of water for domestic purposes. This study aims to study the results of the ability of Zeolit Aerator Filter Aeration. Aeration ability to reduce Iron (Fe) Concentration and Manganese (Mn) Concentration in clean water. This type of research is a literature study, namely by collecting data in the form of secondary data obtained from literature, books and previous research results. The sample in this literature study research is 6 journals related to the title. The results of this study indicate that there are 6 journals about the ability of the Tray Aerator and zeolite filter to reduce levels of Iron (Fe) and Manganese $(\mathrm{Mn})$ in clean water. Based on the results of research in literature studies with 6 journals, the Journal of Aizar and Alfan reduce Fe levels from $0.8 \mathrm{mg} / \mathrm{L}$ to $0.73 \mathrm{mg} / \mathrm{L}$, the journal of Abdul Hafidz $100 \%$ efficiency with aeration can reduce levels to o $\mathrm{mg} / \mathrm{L}$, the journal of Hardini reaches $97 \%$ efficiency.In the Tri Joko's Journal, the iron content of $2.79 \mathrm{mg} / \mathrm{L}$ can be reduced to $0.21 \mathrm{mg} / \mathrm{L}$ with an efficiency of $93 \%$ in the journal of Ronny and Abdul Hafid, from the Fe level of $3.51 \mathrm{mg} / L^{\prime}$ can decrease to $1,12 \mathrm{mg} / \mathrm{L}$.
\end{abstract}

Keywords: Try aerater, zeolite filter, Iron (Fe), Manganese (Mn)

\section{ABSTRAK}

Air merupakan kebutuhan yang tidak bisa ditunda pemenuhannya. Masalah utama yang dihadapi oleh sumber daya air meliputi kuantitas air yang sudah tidak mampu memenuhi kebutuhan yang terus meningkat dan kualitas air untuk keperluan domestic yang semakin menurun. Penelitian ini bertujuan untuk kajian dari hasil kemampuan Aerasi Tray Aerator Filter Zeolit terhadap Penurunan Konsentrasi Besi (Fe) dan Konsentrasi Mangan (Mn) pada air bersih. Jenis penelitian ini adalah studi literatur, yaitu dengan mengumpulkan data berupa data sekunder yang diperoleh dari literatur-literatur, buku-buku dan hasil penelitian sebelumnya. Sampel dalam penelitian dengan studi kepustakaan ini adalah 6 jurnal yang berkaitan dengan judul. Hasil dari penelitian ini menunjukkan bahwa terdapat 6 jurnal tentang kemampuan alat Tray Aerator dan Filter zeolite dinyatakan mampu menurunkan kadar Besi (Fe) dan Mangan (Mn) pada air bersih. Berdasarkan hasil penelitian studi kepustakaan dengan metode studi kepustakaan dengan 6 junal, pada jurnal Aizar dan Alfan menurunkan Kadar Fe 0,8 mg/L menjadi $0,73 \mathrm{mg} / \mathrm{L}$, Jurnal abdul hafidz efisiensi $100 \%$ dengan alat aerasi dapat menurunkan kadar sampai $0 \mathrm{mg} / \mathrm{L}$, jurnal Hardini mencapai efisiensi 97\% Pada jurnal Tri Joko kandungan Besi 2,79 mg/L dapat diturunkan menjdi 0,21 mg/L dengan efisiensi 93\% pada Jurnal Ronny dan Abdul Hafid dari kadar Fe 3,51 mg/L dapat turun menjadi 1,12 mg/L.

Kata Kunci: Besi (Fe), Filter zeolit, Mangan (Mn), Try aerator

\section{PENDAHULUAN}

Air merupakan kebutuhan yang tidak bisa ditunda pemenuhannya. Manusia membutuhkan air, terutama untuk minum. Ketersediaan air di dunia begitu melimpah ruah, namun yang dapat dikomsumsi oleh manusia untuk keperluan air minum sangatlah sedikit. Dari total jumlah air yang ada, hanya lima persen saja yang tersedia sebagai air minum, sedangkan sisanya adalah air laut. Namun di dunia, kecenderungan yang terjadi sekarang ini adalah berkurangnya ketersediaan air bersih itu dari hari ke hari. Semakin meningkatnya populasi, semakin besar pula kebutuhan akan air minum. Sehingga ketersediaan air bersih pun semakin berkurang (Fery Kumlasari dan Yogi Satoto, 2010).

Bagi manusia, air sangat dibutuhkan untuk dikomsumsi. Seseorang yang tidak dapat bertahan hidup tanpa air, karena itulah air merupakan salah satu penopang hidup bagi manusia. Ketersediaan air di bumi begitu melimpah, namun yang dapat digunakan oleh manusia untuk keperluan air bersih dan minum sangatlah sedikit. Dari total jumlah air yang ada, hanya $5 \%$ saja yang tersedia sebagai air bersih, sedangkan sisanya adalah air laut. (Indarto, 2014).

Menurut hasil penelitian World Research Instuitute (WRI) pada tahun 2015 mengenai kondisi ketersediaan air bersih, ada proyeksi bahwa paada tahun 2040 saja dunia sudah berada dalam situasi krisis. Kebutuhan air akan meningkat pesat per tahun karena adanya kebutuhan dari manusia, pertanian, dan industri. WRI juga menyebutkan bahwa perubahan iklim akan membuat beberapa area kering, sedangkan area lainnya semakin basah. 
Jurnal Sulolipu : Media Komunikasi Sivitas Akademika dan Masyarakat

Vol. 21 No.12021

e-issn: 2622-6960, p-issn : 0854-624X

Akibatnya, ada ancaman kekeringan dan banjir. (WRI, 2015)

Badan Pusat Statistik (2018) mengatakan produksi air bersih di Indonesia tahun 2018 sebanyak 4.879.050 ribu $\mathrm{M}^{3}$ dengan jumlah penduduk 265 juta penduduk. Jumlah penduduk Indonesia berdasarkan hasil estimasi pada tahun 2018 sebesar 265.015.313 jiwa, terdiri atas 133.136.131 jiwa penduduk laki- laki dan 131.879.182 jiwa penduduk perempuan. Kurangnya sarana air bersih dan banyaknya sumber pencemar menyebabkan pencemaran di beberapa sumber air seperti sungai dan sumur. Selain itu, tata ruang yang kurang tepat dan tingginya eksploitasi sumber daya air sangat berpengaruh pada kualitas air. Akibatnya tahun 2017 jumlah penderita diare semua umur (SU) yang dilayani di sarana kesehatan sebanyak 4.274.790 penderita dan terjadi peningkatan pada tahun 2018 yaitu menjadi 4.504.524 penderita. (Kementerian Kesehatan 2018).

Mengingat bahwa air sumur ini sangat banyak digunakan oleh masyarakat, maka diperlukan beberapa upaya penyempurnaan sumur gali dalam rangka memenuhi syarat kesehatan dan tidak menimbulkan gangguan terhadap . (Suparyanto, 2014)

Masalah utama yang dihadapi oleh sumber daya air meliputi kuantitas air yang sudah tidak mampu memenuhi kebutuhan yang terus meningkat dan kualitas air untuk keperluan domestik yang semakin menurun. Kegiatan industri, domestik dan kegiatan lain menyebabkan penurunan kualitas air. Kondisi ini dapat menimbulkan gangguan, kerusakan, dan bahaya bagi semua makhluk hidup yang bergantung pada sumber daya air. Oleh karena itu diperlukan pengelolaan dan perlindungan sumber daya air secara seksama (Fakhrurroja, 2010)

Mangan berada dalam bentuk manganous $\left(\mathrm{Mn}^{2+}\right)$ dan manganik $\left(\mathrm{Mn}^{4+}\right)$. Didalam tanah, $\mathrm{Mn}^{4+}$ berada dalam bentuk senyawa mangan dioksida. Pada perairan dengan kondisi anaerob akibat dekomposisi bahan organik dengan konsentrasi yang tinggi, $\mathrm{Mn}^{4+}$ pada senyawa mangan dioksida mengalami reduksi menjadi $\mathrm{Mn}^{2+}$ yang bersifat larut. $\mathrm{Mn}^{2+}$ berikatan dengan nitrat, sulfat, dan klorida dan larut dalam air.

Dampak dari terpaparnya air yang mengandung bahan kimia seperti cadmium, besi, dan mangan dalam bentuk kronis maupun akut. Dalam jangka waktu pendek, zat-zat tersebut dapat menimbulkan gangguan system pernafasaan seperti lemas, batuk, sesak napas, bronchopneumonia, edema paru, dan cyanosis serta methemoglobinemia. Dampak penyimpangan parameter zat kimia adalah dapat meningkatkan reaktivitas pada pembuluh tengorokan dan sensitivitas pada penderita asma. Zat kimia bersifat racun terutama terhadap paru dengan diawali gangguan pada pernafasan. (Pahruddin, 2017)

Metode pengolahan air yang dapat digunakan dalam menurunkan besi dan mangan yaitu dengan oksidasi dan presipitasi, penambahan bahan kimia dan pengendapan serta filtrasi, dan penukaran ion. Besi Ferro $\left(\mathrm{Fe}^{2+}\right)$ dan Mangan Manganous $\left(\mathrm{Mn}^{2+}\right)$ adalah terlarut, bentuk yang tidak terlihat, mungkin terdapat dalam air sumur atau air yang anaerobik. Apabila kontak dengan udara, bentuk ini teroksidasi berubah perlahan menjadi bentuk yang tidak terlarut, bentuk kelihatan nyata, besi teroksidasi, Ferri dan Mangan. Ferri dan Mangan teroksidasi tersebut dapat seluruhnya dihilangkan dengan proses pengendapan dan penyaringan (Joko, 2010).

Aerasi adalah proses pengolahan air dengan cara mengkontakkannya dengan udara. Aerasi secara luas telah digunakan untuk pengolahan air yang mempunyai kandungan jumlah besi dan mangan terlalu tinggi (mengurangi kandungan konsentrasi zat padat terlarut). Zat-zat tersebut memberikan rasa pahit pada air, menghitamkan alat-alat masak dan memberikan noda hitam, kecoklatan- coklatan pada pakaian yang dicuci (Ronny, 2016).

Penyaringan (filtrasi) adalah salah satu cara pemisahan zat baik berupa cairan maupun gas. Pemisahan zat padat dari campuran padat cair dilakukan dengan bantuan medium berpori yang disebut medium penyaring. Suspensi padat cair dipaksa melewati medium penyaring. Zat padat akan tertahan medium penyaring, sedangkan cairan dapat melewatinya yang biasa disebut filtrat. Dalam beberapa penyaringan, padatan-saring yang terbentuk merupakan medium penyaring yang baik. 
Jurnal Sulolipu : Media Komunikasi Sivitas Akademika dan Masyarakat

Vol. 21 No.12021

e-issn: 2622-6960, p-issn : 0854-624X

\section{METODE}

\section{Jenis Penelitian}

Jenis penelitian ini adalah Studi literatur dengan metode studi kepustakaan (Library Research).

\section{Gambaran Umum}

Waktu penelitian terbagi atas dua tahap, yaitu:

a. Tahap persiapan yang meliputi pengumpulan data dan penyusunan proposal yang berlansung pada bulan Desember - Januari 2020.

b. Tahap pelaksanaan meliputi kegiatan penelitian yang berlansung pada bulan Februari - April 2020.

\section{Sumber Data}

Data diperoleh dari data sekunder yang menjadi data primer yang diperoleh dari literatur-literatur berupa jurnal, buku-buku, maupun data lainnya yang berhubungan dengan peneltian.

\section{Pengolahan dan Penyajian Data}

Pegolahan data dilakukan dengann menggunakan Komputer dan hasil dari penelitian sebelumnya sehingga data yang diperoleh kemudian disajikan dalam bentuk table.

\section{Analisis Data}

Teknik analisis data dalam peneltian ini adalah metode analisis isi (content analysis). Analisis ini digunakan untuk mendapatkan inferensi yang valid dan dapat diteliti ulang berdasarkan kontaknya. Untuk menjaga kekekalan proses pengkajian dan mencegah serta mengatasi misinformasi (kesalahan pengertian manusiawi yang bisa terjadi karena kekurangan pengetahuan peneliti atau kekurangan penulis Pustaka) maka dilakukan pengecekan antar Pustaka dan membaca ulang Pustaka serta memperhatkan komentar pembimbing

\section{HASIL}

penelitian tentang kemampuan alat dengan proses aerasi untuk menurunkan konsentrasi Besi ( $\mathrm{Fe})$ dan Mangan (Mn) dari beberapa hasil penelitian sebelumnya, yaitu.

Tabel 1

Analisis Penurunan Kadar Besi (Fe) dengan Menggunakan Tray Aerator dan Diffusser Aerator (2015)

\begin{tabular}{cccccc}
\hline No & Jenis Aerator & Menit Ke & $\begin{array}{c}\text { Kadar Fe } \\
(\mathbf{m g} / \mathbf{l})\end{array}$ & $\begin{array}{c}\text { Nilai PV } \\
(\mathbf{m g} / \mathbf{l})\end{array}$ & $\begin{array}{c}\text { Efisiensi } \\
\text { Kadar } \\
\text { Penyisihan } \\
\text { Besi (Fe) }\end{array}$ \\
\hline $\mathbf{1 .}$ & & awal & 0,80 & 24,80 & \\
\hline $\mathbf{2 .}$ & Tray aerator 5 tingkat & 0 & 0,73 & 18,96 & $10 \%$ \\
\hline 3. & & & & \\
\hline 4. & & 4 & 0,72 & 16,74 & \\
\hline
\end{tabular}

Sumber : Data primer Aizar Lutfihani dan Alfan Purnomo 2015 (Analisis Penurunan Kadar Besi (Fe) dengan Menggunakan Tray aerator dan Diffuser Aerator 
Jurnal Sulolipu : Media Komunikasi Sivitas Akademika dan Masyarakat

Vol. 21 No.12021

e-issn: 2622-6960, p-issn : 0854-624X

Table 2

Efektivitas Pengolahan Air Bersih Menggunakan Tray Aerator Dalam Menurunkan Konsentrasi Fe, Mn, Ph Pada Air Sumur Gali (2019)

\begin{tabular}{|c|c|c|c|c|c|c|c|}
\hline No & $\begin{array}{c}\text { Jenis } \\
\text { Aerator }\end{array}$ & $\begin{array}{c}\text { Sebelum } \\
\text { kadar Fe } \\
(\mu g \backslash L)\end{array}$ & $\begin{array}{l}\text { Rata- } \\
\text { rata }\end{array}$ & $\begin{array}{c}\text { Kadar } \\
\text { maksimum } \\
\text { yang } \\
\text { diperbolehkan }\end{array}$ & $\begin{array}{l}\text { Sebelum } \\
\text { kadar } \\
\mathrm{Mn} \\
(\mu \mathrm{g} \backslash \mathrm{L})\end{array}$ & $\begin{array}{l}\text { Sesudah } \\
\text { kadar } \\
\text { Mn } \\
(\mu g \backslash L)\end{array}$ & $\begin{array}{c}\text { Kadar maksimum } \\
\text { yang } \\
\text { diperbolehkan }\end{array}$ \\
\hline & Kontrol & 64,810 & & & 182,421 & & \\
\hline 1. & $\begin{array}{c}\text { Tray } \\
\text { aerator } 3 \\
\text { tingkat }\end{array}$ & 92.877 & 60,100 & 1000 & 75.14 & 68.920 & 500 \\
\hline 2. & $\begin{array}{c}\text { Tray } \\
\text { aerator } 5 \\
\text { tingkat }\end{array}$ & 82.85 & 11,427 & 1000 & 71.596 & 67.493 & 500 \\
\hline 3. & $\begin{array}{c}\text { Tray } \\
\text { aerator } 7 \\
\text { tingkat }\end{array}$ & 85.839 & 68,766 & 1000 & 78.025 & 68,154 & 500 \\
\hline
\end{tabular}

Sumber : Data primer Zairinayati dan Nur Afni Maftukhah 2019 (Efektivitas Pengolahan Air Bersih Menggunakan Tray Aerator Dalam Menurunkan Konsentrasi Fe, Mn, Ph Pada Air Sumur

Table 3

Pengaruh Aerasi Bertingkat Dengan Kombinasi Saringan Pasir, Karbon Aktif, Dan Zeolit Dalam Menyisihkan Parameter Fe Dan Mn Dari Air Tanah

\begin{tabular}{|c|c|c|c|c|c|c|c|}
\hline \multirow[b]{3}{*}{ No } & & \multicolumn{3}{|c|}{ Percobaan Pertama } & \multicolumn{3}{|c|}{ Percobaan kedua } \\
\hline & & \multicolumn{3}{|c|}{ Kadar Fe(mg/L) } & \multicolumn{3}{|c|}{ Kadar Fe(mg/L) } \\
\hline & $\begin{array}{l}\text { Waktu } \\
\text { Samplin } \\
g\end{array}$ & $\begin{array}{c}\text { Sebelu } \\
\text { m }\end{array}$ & $\begin{array}{c}\text { Sesuda } \\
\text { h (setiap } \\
\text { satu jam } \\
\text { dalam } 5 \\
\text { jam) }\end{array}$ & $\begin{array}{c}\text { Efisiensi } \\
\text { penuruna } \\
\text { n kadar } \\
\text { Fe (\%) }\end{array}$ & $\begin{array}{c}\text { sebelu } \\
\mathrm{m}\end{array}$ & $\begin{array}{c}\text { Sesuda } \\
\text { h (setiap } \\
\text { satu jam } \\
\text { dalam } 5 \\
\text { jam) }\end{array}$ & $\begin{array}{c}\text { Efisiensi } \\
\text { penuruna } \\
\text { n kadar } \\
\text { Fe (\%) }\end{array}$ \\
\hline \multirow{5}{*}{1} & 08.00 & & 0,4 & $44,44 \%$ & \multirow{5}{*}{0,5084} & 0,4511 & $11,27 \%$ \\
\hline & 09.00 & \multirow{4}{*}{$0,72 \mathrm{mg}$} & 0,41 & $43,06 \%$ & & 0.3914 & $23,01 \%$ \\
\hline & 10.00 & & 0,38 & $47,22 \%$ & & 0,3973 & $21,86 \%$ \\
\hline & 11.00 & & 0,41 & $43,06 \%$ & & 0,3899 & $23,31 \%$ \\
\hline & 12.00 & & 0,42 & $41,67 \%$ & & 0,4235 & $16,70 \%$ \\
\hline \multirow[b]{3}{*}{ No } & & \multicolumn{3}{|c|}{ Percobaan Pertama } & \multicolumn{3}{|c|}{ Percobaan kedua } \\
\hline & & \multicolumn{3}{|c|}{ Kadar Mn(mg/L) } & \multicolumn{3}{|c|}{ Kadar Mn(mg/L) } \\
\hline & $\begin{array}{c}\text { Waktu } \\
\text { Samplin } \\
\quad \mathrm{g}\end{array}$ & $\begin{array}{l}\text { Sebelu } \\
\text { m }\end{array}$ & $\begin{array}{c}\text { Sesuda } \\
\text { h } \\
\text { (setiap } \\
\text { satu } \\
\text { jam } \\
\text { dalam } 5 \\
\text { jam) }\end{array}$ & $\begin{array}{c}\text { Efisiensi } \\
\text { penuruna } \\
\text { n kadar } \\
\text { Mn (\%) }\end{array}$ & $\begin{array}{c}\text { Sebelu } \\
\text { m }\end{array}$ & $\begin{array}{l}\text { Sesuda } \\
\text { h } \\
\text { (setiap } \\
\text { satu } \\
\text { jam } \\
\text { dalam } 5 \\
\text { jam) }\end{array}$ & $\begin{array}{c}\text { Efisiensi } \\
\text { penuruna } \\
\text { n kadar } \\
\text { Mn (\%) }\end{array}$ \\
\hline \multirow{5}{*}{1} & 08.00 & \multirow{5}{*}{0,10} & 0,10 & $0.00 \%$ & & 0,0519 & $37,49 \%$ \\
\hline & 09.00 & & 0,00 & $100,00 \%$ & & 0.0184 & $77,88 \%$ \\
\hline & 10.00 & & 0,00 & $100,00 \%$ & 0,0830 & 0,0245 & $70,44 \%$ \\
\hline & 11.00 & & 0,00 & $100,00 \%$ & & 0,0302 & $63,57 \%$ \\
\hline & 12.00 & & 0,00 & $100,00 \%$ & & 0,0212 & $74.48 \%$ \\
\hline
\end{tabular}


Jurnal Sulolipu : Media Komunikasi Sivitas Akademika dan Masyarakat

Vol. 21 No.12021

e-issn: 2622-6960, p-issn : 0854-624X

Tabel 4

peningkatan kualitas air sumur gali menjadi air bersih menggunakan filter mangan zeolit dan karbon aktif: studi kasus air sumur gali permukiman

desa banjar po sidoarjo

\begin{tabular}{|c|c|c|c|c|}
\hline \multirow[t]{2}{*}{ No } & & & \multicolumn{2}{|c|}{ Mangan Zeolit } \\
\hline & Parameter & $\begin{array}{l}\text { Konsentrasi } \\
\text { Inlet (mg/L) }\end{array}$ & $\begin{array}{l}\text { Konsentrasi } \\
\text { Outlet (mg/L) }\end{array}$ & $\begin{array}{c}\text { Efisiensi } \\
\text { Penyisihan (\% }\end{array}$ \\
\hline 1 & & 1 & 0,037 & 96,31 \\
\hline & Besi(Fe) & 3 & 0,195 & 93,52 \\
\hline 2 & & 1 & 0,24 & 97,62 \\
\hline & Mangan(Mn) & 2,5 & 0,071 & 97,14 \\
\hline
\end{tabular}

Tabel 5

Variasi Penambahan Media Adsorpsi Kontak Aerasi Sistem Nampan Bersusun (Tray Aerator) Terhadap Kadar Besi (Fe) Air Tanah Dangkal Di Kabupaten Rembang

\begin{tabular}{llllll}
\hline No & \multicolumn{2}{c}{ Jenis Aerator } & $\begin{array}{l}\text { sebelum } \\
\text { perlakuan }\end{array}$ & $\begin{array}{l}\text { setelah } \\
\text { perlakuan }\end{array}$ & $\begin{array}{l}\text { Efisiensi } \\
\text { penurunan }\end{array}$ \\
\hline & $\begin{array}{l}\text { Tray } \\
\text { dengan } \\
\text { zeolite }\end{array}$ & $\begin{array}{c}\text { Aerator } \\
\text { media }\end{array}$ & $2,79 \mathrm{mg} / \mathrm{L}$ & $0,21 \mathrm{mg} / \mathrm{L}$ & $93,93 \%$ \\
& & & &
\end{tabular}

Sumber : Data Primer Tri Joko 2016 (Variasi Penambahan Media Adsorpsi Kontak Aerasi Sistem Nampan Bersusun (Tray Aerator) Terhadap Kadar Besi (Fe) Air Tanah Dangkal Di Kabupaten Rembang)

Table 6

Efektivitas Tray Aerator dalam mengurangi sumur air Besi (Fe) di Kabupaten Gowa, Indonesia

\begin{tabular}{ccccc}
\hline No & Jenis Aerator & $\begin{array}{c}\text { sebelum } \\
\text { perlakuan }\end{array}$ & $\begin{array}{c}\text { setelah } \\
\text { perlakuan }\end{array}$ & $\begin{array}{c}\text { Prensentase } \\
\text { penurunan }\end{array}$ \\
1 & Tray Aerator & $3,51 \mathrm{mg} / \mathrm{L}$ & $1,12 \mathrm{mg} / \mathrm{L}$ & $68,01 \%$
\end{tabular}

Sumber : Data Primer Ronny dan Abdul Hafid Hasim 2018 (Efektivitas Tray Aerator dalam mengurangi sumur air Besi (Fe) di Kabupaten Gowa, Indonesia)

PEMBAHASAN

Pada fokus kajian ini membahas tentang hasil dari penelitian yang telah dilakukan yaitu:

a. Pengolahan dengan Multiple Tray Aerator
Pada jurnal Aizhar Lutfihani dan Alfian Purnomo dari hasil penelitian memperoleh rata-rata penurunan $10 \%$ disetiap 4 menit pengolahan dengan penyisihan kadar 
Jurnal Sulolipu : Media Komunikasi Sivitas Akademika dan Masyarakat

Vol. 21 No.12021

e-issn: 2622-6960, p-issn : 0854-624X

penurunan besi (Fe) menggunakan tray aerator 5 tingkat memiliki persen efisiensi penyisihan yang cukup signifikan.

Pada jurnal Zairinayati dan Nur Afni Maftukhah Untuk parameter $\mathrm{Fe}$ hasil pengukuran didapatkan rata-rata penurunan dari 3 jenis tingkatan didapatkan bahwa pada variasi 5 tingkatan menunjukkan kadar $\mathrm{Fe}$ mengalami penurunan paling tinggi $(11,427$ $\mu \mathrm{g} /$ Liter). Sementara untuk parameter $\mathrm{Mn}$ rata-rata penurunan sangat tinggi dan yang terbesar dari variasi 3 jenis tingkatan aerasi tersebut didapatkan pada penggunaan5 tingkatan $(68,154)$.

Dari hasil uji statistik menunjukkan tidak ada perbedaan dari penggunaan variasi jumlah tray aerator tersebut. Jika dilihat dari sebaran distribusi frekuensi untuk parameter Fe mengalami penurunan angka sebelum dan sesudah dilakukan aerasi tetapi selisih dari penuruan itu hanya pada variasi 3 tingkatan prosentase sebesar $96 \%$, artinya penurunan kadar Fe tersebut sangat kecil $(0,4 \%)$. Sama halnya dengan parameter $\mathrm{Mn}$, jika dilihat dari angka rata-rata $\mathrm{Fe}$ mengalami penurunan angka sebelum dan sesudah dilakukan aerasi pada variasi 3 tingkatan prosentase sebesar $37 \%$.

Pada jurnal Muntu Ronny dengan penelitian pemanfaatan alat Multiple aerator menggunakan aerator baki berganda menghasilkan tingkat nilai rata-rata besi $(\mathrm{Fe})$ sebelum aerator diperoleh $3,51 \mathrm{mg} / \mathrm{L}$ dan kemudian setelah proses diperoleh aerator $1,12 \mathrm{mg} / \mathrm{L}$. Biaya menurunkan tingkat zat besi (Fe) setidaknya melihat pada jumlah sampel 15 yang nilainya turun menjadi 2,27 dengan persentase penurunan $66,18 \%$ dan penurunan maksimum terlihat pada jumlah sampel 4 dengan nilai turun menjadi 2,49 dengan penurunan tarif sebesar $69,55 \%$. Nilai rata-rata penurunan kadar besi $(\mathrm{Fe})$ dari 30 sampel dalam penelitian ini diperoleh 2,39 dengan persentase penurunan rata-rata $68,01 \%$.

Dari hasil yang diperoleh menunjukkan tingkat penurunan kadar rata-rata besi $(\mathrm{Fe})$ sekitar 2,21 mg / L dengan persentase ratarata penurunan $68,01 \%$. Nilai kadar besi $(\mathrm{Fe})$ rata-rata setelah aerasi diperoleh pada 1,12 $\mathrm{mg} / \mathrm{L}$. Meskipun telah terjadi penurunan yang signifikan sebelum dan sesudah aerasi dilakukan tetapi belum persyaratan air bersih dengan nilai kadar besi (Fe) hingga 1,00. Untuk mencapai tingkat besi ( $\mathrm{Fe}$ ) agar sesuai dengan persyaratan, perlu untuk diproses lebih lanjut setelah aerasi. Namun besarnya penurunan kadar besi (Fe) dalam penelitian ini tidak dapat dipisahkan dari situsi yang dibuat pada area reduksi udara yang bersirkulasi pada saat penelitian bertiup dengan baik maka baki jenis aerasi tinggi yang membuat transfer difusi gas Proses terjadi ketika tetesan air yang jatuh pada nampan lubang- lubang untuk aerasi. Kondisi ini dan ditambah dengan jenis aerasi yang digunakan adalah jenis pelat kemudian terlihat hasil yang diperoleh lebih efisien dalam mengurangi kadar besi (Fe) dalam sumur air.

Oksidasi senyawa besi dan mangan dalam air tidak selalu terjadi pada waktu yang tepat. Jika air mengandung zat organik, pembentukan senyawa besi dan mangan melalui proses aerasi akan terlihat sangat tidak efektif (Muntu, 2016)

Aerator dipergunakan untuk menambah konsentrasi oksigen terlarutdi dalam air dengan untuk memperbesar permukaan kontak (contact surface) antara dua medium (air dan udara). Multiple tray aeratoryang terdiri atas 4-8 tray dengan dasarnya penuh lubanglubang pada jarak 30$50 \mathrm{~cm}$. Melalui pipa-pipa berlubang air dibagi rata melalui tray, dari sini percikanpercikan kecil turun ke bawah dengan kecepatan kirakira 0,002 m3/detik per m2 permukaan tray. (Joko, T., 2010)

\section{b. Pengolahan dengan filter zeolit}

Di penelitian Hardini, I. dan Karnaningroem, $\mathrm{N}$ mencoba variasi dengan filtrasi menggunakan media pasir zeolite pada jurnal yang telah dikaji bahwa konsentrasi $\mathrm{Fe}$ $1 \mathrm{mg} / \mathrm{L}$ dan $3 \mathrm{mg} / \mathrm{L}$ lebih efektif dengan menggunakan kedua media, yaitu karbon aktif dan mangan zeolit. Dalam penelitian ini ketebalan media $40 \mathrm{~cm}$ memiliki efisiensi penyisihan yang lebih tinggi dibanding ketebalan $25 \mathrm{~cm}$.

Keefektifan penuranan kadar $\mathrm{Fe}$ dan Mn lebih teruji dengan menggunakan zeolit yang sudah diaktivasi terlebih dahulu. Seperti pada penelitian Karnaningroem dan Hardini (2011) yang melakukan uji filter dengan menggunakan media mangan zeolit dan 
Jurnal Sulolipu : Media Komunikasi Sivitas Akademika dan Masyarakat

Vol. 21 No.12021

e-issn: 2622-6960, p-issn : 0854-624X

karbon aktif. Mangan zeolit ialah zeolit yang sudah diaktivasi terlebih dahulu. Diamater media karbon aktif ialah $1 \mathrm{~mm}$ dan mangan zeolit ialah $2 \mathrm{~mm}$. Perbandingan media ialah $1: 1$ dengan ketebalan $40 \mathrm{~cm}$ dapat menurunkan kadar $\mathrm{Fe}$ dari $1 \mathrm{mg} / \mathrm{l}$ menjadi $0,024 \mathrm{mg} / \mathrm{l}$ atau dengan efisensi penyisihan sebesar $90,31 \%$ dan kadar $\mathrm{Mn}$ dari $1 \mathrm{mg} / \mathrm{l}$ menjadi $0,016 \mathrm{mg} / \mathrm{l}$ atau dengan efisensi penyisihan sebesar $97,62 \%$. Kemampuan zeolit sebagai adsorben untuk menghilangkan mangan dari dalam air lebih besar dibandingkan dengan karbon aktif (Rahmawati, 2009). Daya serap karbon aktif dipengaruhi oleh sifat serapan, suhu, $\mathrm{pH}$, dan waktu kontak (Sembiring dan Tuti, 2003).

$$
\text { Hardini dan Hardini dan }
$$

Karnaningroem (2011) menyatakan dalam penelitiannya bahwa semakin tebal media karbon aktif dan zeolit maka efisiensi penyisihan semakin tinggi. Semakin lama waktu kontak maka semakin bany ak kesempatan partikel karbon aktif untuk bersinggungan dengan logam besi yang terikat di dalam pori-pori karbon aktif (Asbahani, 2013).

\section{c. Pengolahan Kombinasi Tray Aerator dan filter Zeolit \\ Pada jurnal Abdul Hafidz} Nainggolan,Ahmad Perwira Mulia Tarigan dan Hafizhul Khair dengan metode kombinasi alat aerasi dan alat filter dengan judul Pengaruh Aerasi Bertingkat Dengan Kombinasi Saringan Pasir, Karbon Aktif, Dan Zeolit Dalam Menyisihkan Parameter Fe Dan Mn Dari Air Tanah Pada percobaan pertama kadar Fe sesudah melewati alat penyaring air lebih konstan jika dibandingkan dengan percobaan kedua. Hal ini dapat disebabkan jarak pelaksanaan percobaan pertama dengan percobaan kedua yang terlalu lama membuat alat terpengaruh oleh faktor luar. Pada jam kedua saat percobaan kedua penurunan kadar Fe membaik dikarenakan media telah tercuci kembali sejak alat dijalankan.

Keefektifan masing-masing alat terlihat tidak terlalu berbeda dalam menurunkan kadar Fe. Penurunan kadar Fe paling tinggi terdapat pada alat 1 yang berhasil menurunkan kadar Fe dari 0,72 mg/l menjadi $0,38 \mathrm{mg} / \mathrm{l}$ dengan efisiensi sebesar $47,22 \%$.
Untuk kadar mangan efisiensi penurunan $\mathrm{Mn}$ terbesar ialah $100 \%$ pada percobaan pertama dengan menggunakan semua alat dan $93,39 \%$ pada percobaan kedua yang menggunakan alat 2 yaitu aerasi 2 tingkat dengan kombinasi zeolit dilanjutkan dengan saringan pasir, karbon aktif, dan zeolit. Penurunan kadar $\mathrm{Mn}$ baik dalam percobaan pertama maupun percobaan kedua dapat dikatakan baik dan efisien. Meskipun pada percobaan pertama terdapat lima hasil uji kadar Mn sesudah melewati alat penyaring yang belum berubah atau sama dengan kadar $\mathrm{Mn}$ sebelum penyaringan. Alat penyaring air lebih efisien dalam menurunkan kadar $\mathrm{Mn}$ bila dibandingkan dengan penurunan kadar Fe.

Dalam menurunkan kadar $\mathrm{Fe}$ dan $\mathrm{Mn}$, zeolit lebih efektif dibandingkan dengan karbon aktif dan pasir. Sedangkan karbon aktif lebih efektif dibandingkan pasir. Hal ini menjadi pertimbangan peneliti dalam meletakkan susunan media dari bawah ke atas yaitu pasir, karbon aktif, dan zeolit.

Pada jurnal Tri Joko variasi alat aerasi dan filtrasi mampu menurunkan kadar Fe dan Mn. Kadar DO sampel air sebelum aerasi yaitu $5,06 \mathrm{mg} / \mathrm{l}$ dan setelah aerasi meningkat hingga 6,60 mg/l. Rata-rata kadar $\mathrm{Fe}$ sebelum diberi perlakuan yaitu $2,79 \mathrm{mg} / \mathrm{l}$. Rata- rata kadar Fe setelah aerasi dengan penambahan media kontak zeolit yaitu 0,21 $\mathrm{mg} / \mathrm{l}$. Hasil penelitian menunjukkan rata-rata selisih penurunan $\mathrm{Fe}$ pada aerasi dengan pembubuhan media kontak zeolit adalah 2,57 $\mathrm{mg} / \mathrm{l}$ dengan persentase yaitu $93,93 \%$

Rata-rata kadar $\mathrm{Fe}$ setelah aerasi dengan penambahan media kontak karbon aktif yaitu 0,23 mg/l. Rata-rata selisih penurunan dengan pembubuhan media karbon aktif yaitu 2,54 dengan persentase $91,69 \%$. Ratarata selisih penurunan pada perlakuan tidak jauh berbeda dibandingkan dengan perlakuan aerasi dengan pembubuhan media zeolite.

Aerasi dengan penambahan media kontak zeolit memiliki rata-rata efisiensi sebesar 93,93\%. Aerasi dengan penambahan media kontak karbon aktif memiliki rata-rata efisiensi sebesar $91,70 \%$. Penambahan media kontak zeolit memiliki efisiensi yang lebih besar dibandingkan dengan penambahan media kontak karbon aktif pada tray. Aerasi tray dengan 
Jurnal Sulolipu : Media Komunikasi Sivitas Akademika dan Masyarakat

Vol. 21 No.12021

e-issn: 2622-6960, p-issn : 0854-624X

penambahan media kontak zeolit lebih efektif dibandingkan dengan aerasi tray penambahan media karbon aktif.

Tray pada aerator berfungsi untuk memaksimalkan kontak antara air dengan udara yang bertujuan menambah oksigen, sehingga semakin bertambahnya waktu injeksi udara ke dalam air baku akan semakin memaksimalkan terjadinya kontak air dengan udara sehingga oksigen terlarut akan semakin banyak. 9 Metode tray aerator efektif menurunkan kadar Fe karena mempunyai luas bidang kontak antara air dan oksigen lebih besar. Jumlah tray juga memberikan waktu kontak yang lebih lama sehingga $\mathrm{Fe}$ dapat teroksidasi oleh $\mathrm{O} 2$. Pada penelitian ini, penambahan media kontak zeolit dan karbon aktif dapat memberikan efisiensi penurunan $\mathrm{Fe}$ yang tinggi. Hal ini berbeda dengan penelitian- penelitian sebelumnya yang menunjukkan bahwa efisiensi tray aerator tanpa kombinasi media kontak masih dibawah $90 \%$.

Kombinasi media kontak yang bersifat adsorben pada tray aerator terbukti dapat meningkatkan kemampuan aerator untuk menyerap Fe. Hal ini disebabkan oleh media kontak zeolit dan karbon aktif yang bersifat sebagai adsorben logam. Selain itu, proses penurunan kadar $\mathrm{Fe}$ dengan zeolit menggunakan prinsip cation exchanger. Zeolit memiliki kemampuan sebagai ironexchanger dengan menghasilkan reactive oxygen species. Zeolit merupakan mineral alumino silikat tetapi mempunyai struktur lapisan (layer) dan sifat pertukaran ionnya terutama disebabkan gugusan hidroksil dimana ion $\mathrm{H}$ dapat digantikan dengan ion lain.

Dari hasil Telaah dari ke 6 jurnal Alat Tray aertor mampu menurunkan kadar Besi (Fe) dan Mangan (Mn) pada air. Dilihat juga dri jurnal Tri Joko dengan pemanfaatan media zeolite ampuh menunrunkan kadar besi dan Mangan. Dari jurnal-jurnal yang telah diteliti yang dilihat dengan variabel peneltiannya rata-rata menunjukkan hasil yang baik itu didukung dengan pengapliksian teori dengan memaksimalkan keadaan dilapangan.

Seperti yang dijelaskan di Tinjauan Pustaka. Aerasi merupakan proses penjernihan dengan cara mengisikan oksigen kedalam air. Dengan diisijkannya oksigen kedalam air maka zat - zat seperti karbon dioksidad serta hydrogen sulfida dan metana yang mempengaruhi rasa dan bau dari air dapat dikurangi atau dihilangkan. Selain itu partikel mineral yang terlarut dalam air seperti besi dan magan akan teroksidasi dan secara cepat akan dihilangkan melalui proses sedimentasi atau filtrasi (Syamsuddin, 2017).

Filtrasi dalam system pengolahan air bersih/minum adalah proses penghilangan partikel-partikel/flok-flok halus yang lolos dari unit sedimentasi. Dimana peertikelpartikel/flok-flok tersebut akan tertahan pada media penyaring selama air melewati media tersebut. Filtrasi diperlukan untuk menyempurnakan penurunan konsentrasi kontaminan seperti bakteri, warna, rasa, bau, dan $\mathrm{Fe}$, sehingga diperoleh air bersih yang memenuhi standar kualitas air minum.

Zeolit adaalah kristal alumino silikat dari element grup IA dan grup IIA, sepetrti natrium, kalium, magnesium, dan kalsium. Secara kimia zeolit dapat ditulis dengan

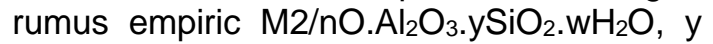
adalah 2 atau lebih besar, $\mathrm{n}$ adalah valensi kation, dan w melambangkan air yang terkandung didalamnya. Struktur zeolit adalah kompleks, yaitu polimer kristal anorganik didasarkan kerangka tetrahedral yang diperluas tak terhingga dari $\mathrm{AlO}_{4}$ dan $\mathrm{SiO}_{4}$ dan dihubungkan satu dengan yang lainnya melalui pembagian Bersama ion oksigen, struktur kerangka ini mengandung saluran yang diisi oleh kation dan molekul air, kation aktif bergerak dan umumnya bertindak sebagai ion exchanger. Air dapat dihilangkan secara reversible yang secara umum dengan pemberian panas. Jika zeolit didasarkan pada satu unit sel kristal, dapat dituliskan sebagai $\left.\mathrm{Mx} / \mathrm{n}\left(\mathrm{AlO}_{2}\right) \times\left(\mathrm{SiO}_{2}\right) \mathrm{y}\right] \cdot \mathrm{wH}_{2} \mathrm{O}$.

Muatan negative inilah yang meyebabkan zeolit mampu mengikat kation. Dengan demikian, dapat digunakan untuk mengikat kation- kation pada air, seperti besi $(\mathrm{Fe})$, aluminium ( $\mathrm{Al}$ ) atau magnesium $(\mathrm{Mg})$ yang umumnya terdapat pada air tanah. Dengan mengalirkan air baku pada filter zeolit, kation akan diikat oleh zeolit yang memiliki muatan negative. Disamping itu, zeolit juga mudah melepas kation dan diganti dengan kation laiinya, misalnya zeolit melepas natrium dan digandikan dengan mengikat kalsium atau magnesium. Dengan 
Jurnal Sulolipu : Media Komunikasi Sivitas Akademika dan Masyarakat

Vol. 21 No.12021

e-issn: 2622-6960, p-issn : 0854-624X

demikian, zeolit berfungsi sebagai ion exchanger dan adsorben dalam pengolahan air.

Zeolit merupakan salah satu bahan kekayaan alam sangat bermanfaat bagi

industry kimia diindonesia. Zeolit ada dua macam, yaitu zeolit alamm dan sinstetik.

\section{DAFTAR PUSTAKA}

Abdul Hafidz, Ahmad Perwira, Hafizhul. 2017. Pengaruh Aerasi Bertingkat Dengan Kombinasi Saringan Pasir, Karbon Aktif, Dan Zeolit Dalam Menyisihkan Parameter Fe dan Mn Pada Air Tanah Di Pesantren Ar-RAudhatul Hasanah. Jurnal Teknik Lingkungan UNAND 14 (1).

Alamsyah Dedi, Muliawati Ratna. 2013. Pilar Dasar IImu Kesehatan Masyarakat. Yogyakarta. Nuha Medika :

Aizar Lutfihani, Alfan Purnomo. 2015. Analisis Penurunan Kadar Besi (Fe) Dengan Menggunakan Tray aerator dan Diffuser Aerator. JURNAL TEKNIK ITS Vol. 4, No. 1

Asmadi, Khayan, Heru Subaris Kasjono. 2011. Teknologi Pengolahan Air Minum, Yogyakarta : Gosypen Publishing.

Budiyono dan Siswo Sumardiono. 2013. Tenik Pengolahan Air. Yogyakarta : Graha IImu.

Elvi S. dkk. 2018. Analisis Paparan Kadmium, Besi, Dan Mangan Pada Air Terhadap Gangguan Kulit Pada Masyarakat Desa Ibul Besar Kecamatan Indralaya Selatan Kabupaten Ogan Ilir. Jurnal Kesehatan Lingkungan Indonesia 17 (2), 2018, 68 - 73

Fakhrurroja, Hanif. 2010. Membuat Sumur Air Di Berbagai Lahan. Jakarta Griya Kreasi.

Fery Kumlasari dan Yogi Satoto. 2010. Teknik Praktis Mengolah Air Kotor Menjadi Air Bersih Hingga Layak Minum. Bekasi-Jawa Barat : Laskar Aksara, Cetakan Pertama

Hardini, Karnaningroem. 2011. Peningkatan Kualitas Air Sumur Gali Menjadi Air Bersih Menggunakan Filter Mangan Zeolit dan Karbon Aktif. Studi Kasus Air Sumur Gali Pemukiman Desa Banjar Sidoarjo. Jurnal Teknik Lingkungan

Indarto. 2014. Hidrologi Dasar Teori Dan Contoh Aplikasi Hidrologi. Jakarta : PT. Bumi Aksara.

Joko Tri. 2010. Unit Produksi Dalam Sistem Penyediaan Air Minum. Yogyakarta : Graha IImu.

Kusnaedi. 2010. Mengolah Air Kotor Untuk Air Minum. Jakarta : Penerbit Swasdaya.

Muntu Ronny. 2016. Penyehatan Air. Makassar : Politeknik Kesehatan Makassar Jurusan Kesehatan Lingkungan.

Mulyani, Happy. 2017. Penuntun Praktik Analisis Dan Optimasi System Penyehatan Air Minum. Yogyakarta: Pustaka Pelajar.

Pahruddin, Muhammad. Risiko Pajanan Logam Berat Pada Air Sungai. Jurnal Kesehatan Lingkungan, 2017, 14(2). 
Jurnal Sulolipu : Media Komunikasi Sivitas Akademika dan Masyarakat

Vol. 21 No.12021

e-issn: 2622-6960, p-issn : 0854-624X

Peraturan Menteri Kesehatan Republik Indonesia Nomor 32 Tahun 2017. Standar Baku Mutu Kesehatan Lingkungan Dan Persyaratan Kesehatan Air Untuk Keperluan Higiene Sanitasi, Kolam Renang, Solus Per Aqua, Dan Pemandian Umum.

Pradana, Tedy Dian. Suharno dan Ardan Kamarullah 2018. Efektivitas Koagulan Bubuk Kapur dan Filtrasi dengan Metode Up Flow dan Down Flow untuk Menurunkan Fe. Jurnal Kesehatan

Profil Kesehatan Indonesia 2018. Health Statistics. Jakarta : Kementerian Kesehatan Indonesia.

Purba, Adi Syahputra. 2018. Pembuatan dan karakterisasi Filter Pemurnian Hidrogen Berbasis Zeolit dengan Filter Serbuk Cangkang Kerang Darah (Anadara granosa). Tesis. Fakultas Matematika dan Ilmu Pengetahuan Alam Universitas Sumatera Utara. Medan. Diakses 28 januari 2020 dari (Online). http://repositori.usu.ac.id/.

Suparyanto. 2014. Masalah air bersih. Diakses 28 januari 2020 dari (Online) http://drsuparyanto.blogspot.com/2014/03/masalah-air-bersih.html..

Suryana H, Rifda. 2013. Analisis Kualitas Air Sumur Dangkal Di Kecematan biringkanayya Kota Makassar. Jurusan Sipil Universitas Hasanuddin Makassar. Diakses pada tanggal 82020 dari (online) https://core.ac.uk/analisis kualitas air sumur dangkal di kecamatan biringkanaya kota Makassar.pdf.

Ronny, Abdul Hafid. 2017. Effetiveness Of Multiple Tray Aertors In Reducing Iron (Fe) water Wells In Gowa Regency, Indonesia. Eco. Env and Cons. 24 (1) : 2018

Sutrisno, Totok. 2006. Teknologi Penyediaan Air Bersih. Jakarta : Rineka Cipta.

Syamsuddin dkk. 2019. Kesehatan Lingkungan Indonesia : Teori Dan Aplikasi. Jakarta : EGC KEDOKTERAN

Tri Joko1, Savitri Rachmawati. 2016. Variasi Penambahan Media Adsorpsi Kontak Aerasi Sistem Nampan Bersusun (Tray Aerator) Terhadap Kadar Besi (Fe) Air Tanah Dangkal di Kabupaten Rembang. JKLI 15 (1)

WRI. 2015. Tiga Perempat Negara Anggota PBB Berbagi Air. Diakses tanggal 28 Januari 2020 dari (Online). http://idntimes.com.

Zairinayati1, Nur Afni Maftukhah. 2019. Efektivitas Pengolahan Air Bersih Menggunakan Tray Aerator Dalam Menurunkan Konsentrasi Fe, Mn, Ph Pada Air Sumur Gali . Jurnal Program Studi DIII Kesehatan Lingkungan, Sekolah Tinggi Ilmu Kesehatan Muhammadiyah Palembang. Volume 3, Nomor 1 , 